\title{
Comunicação pública e participação política: o caso do Disque-Câmara
}

\author{
Public communication and political participation: \\ the case of dial public service of Chamber of Deputies (Brazil)
}

\author{
Antonio Teixeira de Barros ${ }^{[a]}$, Cristiane Brum Bernardes ${ }^{[b]}$, \\ Malena Rehbein Rodrigues ${ }^{[c]}$
}

\footnotetext{
${ }^{[a]}$ Mestre em Comunicação e doutor em Sociologia pela Universidade Nacional de Brasília (UnB), docente e pesquisador do Programa de Pós-Graduação do Centro de Formação da Câmara dos Deputados (CEFOR), Brasília, DF - Brasil, e-mail: antonibarros@gmail.com

[b] Mestra em Comunicação e Informação e doutora em Ciência Política pelo Instituto de Estudos Sociais e Políticos da Universidade Federal do Rio de Janeiro (IESP/UERJ), Rio de Janeiro, RJ - Brasil, e-mail: cris.brum@gmail.com

[c] Mestra em Comunicação e doutora em Ciência Política pelo Instituto de Estudos Sociais e Políticos da Universidade Federal do Rio de Janeiro (IESP/UERJ), Rio de Janeiro, RJ - Brasil, e-mail: malena.rehbein@gmail.com
}

\section{Resumo}

Este artigo discute como a comunicação pública pode contribuir para consolidar projetos de transparência política e de participação social. Para a análise empírica foi selecionado o mecanismo que apresenta os maiores índices de participação: o serviço telefônico gratuito (0800), que registrou mais de 5 milhões de atendimentos de 1998 a 2011. O levantamento apresenta o perfil dos cidadãos que participam, suas principais demandas, temas de maior manifestação e a região geográfica do cidadão. Conclui que, apesar de seu potencial para promover a transparência e a interatividade, a comunicação pública, no caso em estudo, ainda é limitada, pois a eficácia política de seus instrumentos depende da reconfiguração de um arranjo institucional e político que priorize a participação social e os fluxos democráticos de informação.

Palavras-chave: Representação e participação, Participação e democracia, Representação política, Poder Legislativo, Câmara dos Deputados. 


\begin{abstract}
Discusses how communication can help consolidate public projects of political transparency and social participation. For the empirical analysis we selected the mechanism that provides the highest levels of participation: the free telephone service (0800), which recorded more than five million visits from 1998 to 2011. The survey shows the profile of citizens who participate, their main demands, issues of greatest manifestation and geographical region of the citizen. It concludes that, despite its potential to promote transparency and interactivity, public communication, in our case, is still limited because the effectiveness of its policy instruments depends on the reconfiguration of an institutional arrangement that prioritizes political and social participation and democratic flow of information.
\end{abstract}

Keywords: Representation and participation. Participation and democracy. Political representation. Legislature. Chamber of Deputies.

\section{Introdução}

A história política brasileira é marcada por um deficit histórico de participação, transparência e accountability, em decorrência de um longo período de disjunção entre o Estado e a sociedade (DINIZ, 2000). Contudo, com o cenário político redesenhado na redemocratização, especialmente após a promulgação da Constituição de 1988, várias iniciativas começaram a ser implementadas, desencadeando um processo de aproximação das instituições do Estado com a sociedade civil, o que inclui, inevitavelmente, a comunicação e a livre manifestação. Como reflexo direto nas instituições públicas brasileiras surgiram sistemas próprios de informação, sem intermediação de terceiros, para informar os cidadãos sobre as atividades das instituições públicas dos Três Poderes da República.

Contudo, na fase inicial de implantação dessas mídias (1990), a ênfase foi na emissão de conteúdos, com a institucionalização de veículos e canais de informação (rádio, TV, jornal impresso e sistemas online, com o avanço da internet). Tal iniciativa tinha como argumento central o princípio constitucional da publicidade, instituído pela Constituição de 1988, segundo o qual o cidadão tem direito à publicidade dos atos, decisões e demais atividades das instituições vinculadas ao Estado, como ocorre em todos os sistemas de governo representativos. Mais recentemente, com o fenômeno das mídias digitais foram redefinidas as estratégias de comunicação pública, com valorização das manifestações provenientes da sociedade, com o propósito de estabelecer um diálogo institucional com a sociedade, por meio de estratégias de comunicação pública (ZÉMOR, 1995). Nesse cenário tecnológico e sociomediático recente, o projeto de comunicação institucional da Câmara foi redefinido, a fim de oferecer canais de interatividade e participação política e social.

A partir desse contexto institucional mais abrangente, este artigo tem como objetivo analisar como a comunicação pública pode contribuir para consolidar projetos de transparência política e de participação social. Para a análise empírica foi selecionado o mecanismo que apresenta os maiores índices de participação ${ }^{1}$ : o serviço telefônico gratuito (0800) - Disque-Câmara-que registrou mais de cinco milhões de atendimentos de 1998 até o fim de 2011. Trata-se do primeiro canal de interatividade criado pela instituição em 1998 e ainda hoje é reconhecido

\footnotetext{
O projeto de comunicação institucional da Câmara pode ser definido como um sistema híbrido, que combina veículos convencionais de informação (rádio, jornal, TV e jornalismo online), além de atividades de relações públicas, com serviços de atendimento ao cidadão e instituições da sociedade civil. Em abril de 2012 foi criada a Coordenação de Participação Popular, a qual passou a gerenciar o Disque-Câmara, com a missão de aumentar a eficácia política desse e dos demais canais de interatividade e participação social.
} 
como o mais popular e mais democrático, uma vez que a ligação é gratuita, de qualquer localidade do País e atende inclusive aos cidadãos analfabetos ou de pouca escolaridade, sem acesso à internet ou às redes sociais. $\mathrm{O}$ objetivo institucional é facilitar a comunicação do cidadão com a Câmara no que se refere a informações sobre projetos de leis, agenda de votações, composição das bancadas, acompanhamento de tramitação de projetos, informações sobre eventos, como audiências públicas, seminários etc. As funções foram sendo revistas, ampliadas e redefinidas ao longo do tempo, de modo a torná-lo um serviço de participação e não apenas uma central de atendimento. O levantamento quantitativo apresenta o perfil dos cidadãos que participam, suas principais demandas, os temas de maior manifestação e a região geográfica do cidadão.

\section{Comunicação pública, publicidade $\mathrm{e}$ participaçã̃o política}

O histórico dos canais de participação da Câmara está diretamente relacionado às iniciativas institucionais respaldadas pelo princípio constitucional da publicidade. A transparência em relação às ações de governo já foi devidamente defendida por autores renomados, inclusive Norberto Bobbio (2005, p. 28), segundo o qual: "o poder político é o poder público [...] mesmo quando não é público, não age em público, esconde-se do público, não é controlado pelo público ". Para Bobbio (2005, p. 28), a República diferencia-se dos regimes autoritários ou absolutistas exatamente porque há um controle público do poder e a livre formação de uma opinião pública.

No contexto brasileiro recente, para cumprir a obrigatoriedade da publicidade de suas ações e, ao mesmo tempo, possibilitar a participação social, as instituições públicas dos Três Poderes desenvolveram uma série de estratégias que incluem desde a tradicional assessoria de imprensa até os novos veículos de mídia institucionais, passando por campanhas de publicidade institucional e promoção de eventos, entre outras, embora a tônica do projeto político tenha sido na publicidade, ou seja, na divulgação de informações. Várias são as iniciativas que se enquadram nesse escopo, exemplificadas pelas chamadas "mídias das fontes" (SANT"ANNA, 2008), isto é, sistemas de informação mantidos pelas próprias instituições que atuam como fontes de informação, a exemplo do aparato informacional dos poderes Executivo, Legislativo e Judiciário.

A Câmara dos Deputados seguiu essa trilha inicial, com a ênfase nos serviços de distribuição de informação, mas ao mesmo tempo procurou atender ao princípio da reflexividade política e social, com a implantação de mecanismos voltados para captar as manifestações e opiniões da população, com base nos pressupostos da chamada comunicação pública, a qual apregoa que o vetor mais importante é aquele que se estabelece da sociedade para a instituição e não o contrário (ZÉMOR, 1995). Essa é uma das formas de se empreender um projeto de participação social, na perspectiva acima apontada, ou seja, de uma estrutura gerencial capaz de promover o diálogo institucional dos representantes com os representados.

Entre essas iniciativas está o Disque-Câmara, serviço de atendimento telefônico gratuito oferecido à população, desde 1998. O serviço foi criado com $\mathrm{o}$ intuito de propiciar formas de interação entre os cidadãos e os parlamentares e, portanto, possibilitar o diálogo entre as esferas de representação política e participação social. Trata-se de um misto de ouvidoria social, serviço de atendimento, tira-dúvidas, sistema de fornecimento de informações personalizadas, além de um mecanismo para receber e captar sugestões da sociedade, o que permite caracterizá-lo como um mecanismo de participação social e política, com base no pressuposto de que a participação por meio dos canais de interatividade de uma instituição legislativa contribui para aproximar o cidadão do Poder Legislativo, além de oferecer subsídios, com base na opinião e na avaliação dos eleitores, para aqueles que atuam como representantes políticos dos diferentes segmentos da sociedade.

Em uma instituição do Estado, a comunicação institucional assume um caráter ainda mais público e amplo, pois o interesse primeiro da instituição é a continuidade da prestação do serviço ao cidadão. Segundo PierreZémor, uma das finalidades principais da comunicação pública, isto é, aquela feita pelas instituições públicas, é exatamente o esclarecimento da população sobre o funcionamento institucional, dos valores e das funções das diferentes instituições e sobre os debates dos projetos de mudança institucional e de políticas públicas (ZÉMOR, 1995). A partilha de informações de utilidade pública, portanto, é um dos objetivos centrais da comunicação pública. 
A importância do estabelecimento de canais de comunicação entre sociedade e instituições políticas é um dos pontos destacados pelos teóricos que criticam as concepções liberais de democracia, em especial aquelas relacionadas à democracia representativa. Habermas (1994) aponta a necessidade de criação de ferramentas que possibilitem a participação da população nas decisões políticas. O papel da comunicação nessa perspectiva é estratégico, uma vez que o processo político se apoia, decisivamente, na atividade comunicativa colocada em prática na sociedade, com possibilidades de interação e deliberação pública. A comunicação necessária à deliberação pública inclui os atores periféricos ao sistema político, tais como grupos marginalizados e excluídos do sistema representativo formal.

\section{Análise dos dados}

A análise dos dados apresenta os aspectos mais relevantes sobre o atendimento, desde a evolução histórica, a tipologia das demandas sociais, perfil dos cidadãos que participam e o ranking dos projetos de lei de maior interesse dos usuários do Disque-Câmara. A análise tem como base o levantamento sobre o total de atendimentos prestados à população, pelo 0800-619619, desde que o serviço foi criado, em 1998 até o ano 2011, o que totaliza 5.124.310 (5 milhões, 124.310) atendimentos.

\section{Evolução quantitativa do atendimento no período de 1998 a 2011}

Desde que o serviço foi criado, em 1998, a participação social tem sido crescente, como mostra o Quadro 1, com três momentos de sequências de altas, ou seja, do segundo ao sexto ano (1999 a 2003); do sétimo ano ao décimo ano (2004 a 2007) e nos três anos mais recentes (2009 a 2011). Percebe-se, portanto, um recuo relativo na participação nos anos de 2003 , início do governo Lula, e novamente em 2008, ano de eleições municipais. Estes dois fatos explicam a queda nos níveis de participação, uma vez que no primeiro ano de governo Lula muitos movimentos sociais ficaram em estado de espera para analisar as definições sobre os rumos do Executivo e do estabelecimento de suas relações com Judiciário e, especialmente, com o Legislativo. Já em 2008, durante as eleições municipais, muitos parlamentares concorreram ao pleito, o que provocou uma troca considerável nas bancadas, com a entrada de suplentes. Além disso, é justificável que os cidadãos estejam mais interessados no contato com seus representantes locais nesse período do que com os deputados federais.

\section{Levantamento da participação por região geográfica e unidades da Federação}

Do ponto de vista geográfico, os dados mostram prevalência de cidadãos das regiões Sudeste $(46,90 \%)$, Nordeste $(28,30 \%)$ e Sul $(12,60 \%)$, ou seja, as regiões mais populosas e com o maior eleitorado, consequentemente (Quadro 2). Os dados segmentados por estado também refletem, além da concentração geográfica do eleitorado, a tradição de participação política, especialmente no caso de São Paulo, Minas, Pernambuco e Bahia, unidades da federação reconhecidas na historiografia política brasileira como berço de rebeliões, revoltas e manifestações políticas importantes, conforme analisa Boris Fausto (1994).

Quadro 1 - Demonstrativo da média de atendimento

\begin{tabular}{c|c|c|c}
$\begin{array}{c}\text { Total de } \\
\text { Atendimento Anual }\end{array}$ & $\begin{array}{c}\text { Média mensal } \\
\text { de Atendimento }\end{array}$ & $\begin{array}{c}\text { Média diária } \\
\text { de Atendimento }\end{array}$ \\
\hline 1998 & 9.800 & 817 & 41 \\
\hline 1999 & 71.537 & 5.961 & 298 \\
\hline 2000 & 83.820 & 6.985 & 349 \\
\hline 2001 & 87.815 & 7.318 & 366 \\
\hline 2002 & 89.420 & 7.452 & 373 \\
\hline 2003 & 82.912 & 6.909 & 345 \\
\hline 2004 & 504.539 & 42.045 & 2.102 \\
\hline 2005 & 541.318 & 45.110 & 2.255 \\
\hline 2006 & 614.301 & 51.192 & 2.560 \\
\hline 2007 & 617.172 & 51.431 & 2.572 \\
\hline 2008 & 547.617 & 45.635 & 2.282 \\
\hline 2009 & 620.976 & 51.748 & 2.587 \\
\hline 2010 & 725.393 & 60.449 & 3.022 \\
\hline 2011 & 734.948 & 61.246 & 3.062 \\
\hline Total & 5.331 .568 & & \\
\hline
\end{tabular}

Fonte: Pesquisa de campo / base de dados Câmara Federal. 
Quadro 2 - Distribuição do eleitorado x participação 0800

\begin{tabular}{c|c|c|c}
\hline Região & $\begin{array}{c}\mathbf{N}^{\text {o de }} \\
\text { Eleitores }\end{array}$ & Percentual & $\begin{array}{c}\text { Participação } \\
\text { Disque-Câmara }\end{array}$ \\
\hline $\mathrm{CO}$ & 9.402 .084 & $7,10 \%$ & $7 \%$ \\
\hline $\mathrm{N}$ & 9.661 .018 & $7,29 \%$ & $3 \%$ \\
\hline $\mathrm{NE}$ & 35.788 .230 & $27,02 \%$ & $33 \%$ \\
\hline $\mathrm{S}$ & 19.836 .925 & $14,98 \%$ & $12 \%$ \\
\hline $\mathrm{SE}$ & 57.778 .292 & $43,62 \%$ & $46 \%$ \\
\hline Total & 132.466 .549 & $100 \%$ & $100 \%$ \\
\hline
\end{tabular}

Fonte dos dados eleitorais: TSE, 2010.

Além da concentração demográfica e densidade eleitoral, as regiões com maior participação apresentam uma configuração política com características específicas, como uma elite parlamentar consolidada e tradição em participação. Conforme Messenberg (2008), há três agrupamentos na elite parlamentar brasileira: Nordeste, Sudeste e Sul. O primeiro se caracteriza pela presença de representantes dos grandes partidos de orientação ideológica de centro ou de direita, com vínculos estreitos com as administrações estaduais e municipais, além de apresentarem vasta experiência na vida pública local e regional. $\mathrm{O}$ segundo apresenta maior diversidade de filiação partidária, com uma carreira política construída nas capitais dos estados, com posições do alto escalão de empresas e órgãos públicos locais. $\mathrm{O}$ terceiro tem como marca a origem do interior, embora com características similares à elite do Sudeste.

Cabe ressaltar, ainda, que região é território de demarcação de identidade, espaço de formação de províncias de sentidos, de transações simbólicas, a partir de configurações relacionais próprias dos arquipélagos culturais. Apesar dos seus limites e fronteiras, do ponto de vista físico e político, uma região também se caracteriza pelas dinâmicas de mobilidades e expansões, que desencadeiam fluxos e entrecruzamentos de informações. Assim, a escala local se articula com a escala paroquial e esta, por sua vez, com as macroescalas sociais e políticas (HANNERZ, 1997). No Brasil, o que se observa é que as regiões do centro-sul apresentam maior dinamismo de integração e cooperação geocultural e política, enquanto a Região Norte fica à margem de alguns dos fluxos sociais, em razão de sua extensão, localização e dificuldades de transportes e de comunicação. Portanto, não se trata apenas da correlação entre o número de manifestações e o percentual de eleitores ou da densidade populacional, mas também dos demais condicionantes socioculturais que interferem na ecologia política que se estabelece entre as esferas da participação e da representação.

No plano estadual, os casos emblemáticos de participação correspondem aos mais populosos de cada de região e também do País, além de sediarem algumas cidades que exercem papel relevante do ponto de vista econômico, político e cultural. Muitas delas são metrópoles que exercem um peso ou contrapeso expressivo no jogo político nacional e subnacional, a exemplo de São Paulo, Rio de Janeiro e Belo Horizonte. Além disso, é no espaço das metrópoles que se consolida a cultura de participação social no Brasil, o que se explica pela maior facilidade de formação e manutenção das redes de solidariedade e de ativação das relações de sociabilidade política, a exemplo das organizações em torno do orçamento participativo (AVRITZER, 2000). Afinal, a cidade é locus da cultura cívica, o espaço de negociações morais que fomentam e cultivam a participação, uma vez que o próprio espaço urbano favorece a organização e a visibilidade dos movimentos associativos, potencializando a eficácia coletiva da ação desses grupos. A maior participação dos estados mencionados, portanto, deve ser analisada á luz desse cenário mais amplo.

\section{Perfil dos cidadãos que participam e interagem com a Câmara}

Quanto ao perfil, os cidadãos que ligam para o Disque-Câmara são, em sua maioria, do gênero feminino (53\%), na faixa etária de 31 a 49 anos $(57 \%)$ e com ensino superior $(50 \%)$, como mostra o Gráfico 1.

O Gráfico 2 mostra que existem algumas correlações entre o perfil dos cidadãos que ligam para o Disque-Câmara. Os percentuais praticamente são coincidentes no que se refere a gênero. Nas demais variáveis, as diferenças também se explicam pela especificidade da escala usada pelo TSE e pelo Disque-Câmara. 


\begin{tabular}{r|c}
\hline $\mathrm{M}$ & $48 \%$ \\
\hline $\mathrm{F}$ & $52 \%$ \\
\hline Até 30 & $41 \%$ \\
\hline $31-39$ & $43 \%$ \\
\hline 50 & $16 \%$ \\
\hline Fund. & $40 \%$ \\
\hline Médio & $33 \%$ \\
\hline Sup. & $20 \%$ \\
\hline
\end{tabular}

Gráfico 1 - Perfil dos Cidadãos

Fonte: Pesquisa de campo / base de dados Câmara Federal.

\begin{tabular}{r|c}
\hline $\mathrm{M}$ & $48 \%$ \\
\hline $\mathrm{F}$ & $52 \%$ \\
\hline Até 30 & $41 \%$ \\
\hline $31-39$ & $43 \%$ \\
\hline 50 & $16 \%$ \\
\hline Fund. & $40 \%$ \\
\hline Médio & $33 \%$ \\
\hline Sup. & $20 \%$ \\
\hline Outros & $20 \%$ \\
\hline
\end{tabular}

Gráfico 2 - Perfil dos Eleitores

Fonte: Pesquisa de campo / base de dados Câmara Federal.

Mesmo sem considerarmos a distribuição demográfica e por classe social da sociedade brasileira, é fácil perceber que há uma parcela da população que, efetivamente, participa mais nos canais da Câmara. No caso da variável escolaridade, é tangível a correlação entre mais anos de estudo e mais oportunidades de participação política. Provavelmente, o nível de informação sobre a disponibilidade dos serviços seja maior entre os cidadãos com maior instrução, mas também é possível perceber que o próprio interesse pelas formas de participação política é maior nesse segmento. Mais um dado empírico a reforçar a necessidade de ampliação da escolaridade da população brasileira.

Outro dado interessante diz respeito à faixa etária dos participantes, com mais da metade deles em idade produtiva. Em outras palavras, a partir do cruzamento dos dados, são os trabalhadores dos estratos superiores e os integrantes da classe média os maiores participantes junto ao Disque-Câmara. Por outro lado, os cidadãos que participam parecem ser também aqueles com interesses específicos relacionados aos temas em debate na instituição, isto é, aqueles que são diretamente afetados pelas decisões legislativas.

Como mostra o Gráfico 1, o público que configura esse contexto tem, em sua maioria, ensino superior (50\%) ou médio (39\%). Ou seja, são estratos populacionais com melhor nível de formação e informação que estão atuando claramente de forma corporativa e (ou) pessoal. Pode-se imaginar que as participações em temas mais amplos e profundos aconteçam em espaços de discussão como partidos e associações, mas não é possível afirmar que o canal de participação criado pela Câmara favoreça o debate sobre questões nacionais e de interesse geral. Tal limitação se explica por vários fatores técnicos, institucionais e políticos. Do ponto de vista técnico, há que se considerar as restrições inerentes ao próprio canal, que atomiza a participação e não permite interação entre os cidadãos e muito menos acesso direto aos gabinetes parlamentares. Há filtros e protocolos que, ao mesmo tempo que funcionam como pré-condições para viabilizar a participação, também podem resultar em barreiras e ruídos políticos. Sob o ângulo institucional, observa-se que o projeto gerencial da instituição ainda está em construção, o que dificulta o aproveitamento da participação social. Quanto à perspectiva política, talvez o aspecto mais relevante seja a cultura parlamentar calcada na autonomia do gabinete e do mandato, o que faz com que cada um dos 513 gabinetes funcione como uma ilha, sem vínculo com o projeto institucional de estímulo à participação social.

Comparando-se os dados do perfil dos cidadãos com o perfil do eleitorado, percebe-se que, do ponto de vista da distribuição regional, a participação é coerente com a distribuição do eleitorado (Quadro 2). Os percentuais são coincidentes apenas no caso da Região Centro-Oeste, mas observa-se a aproximação em todas elas, com variações entre 5\% e 3\%. Apesar da correlação aparentemente óbvia, os dados reiteram o pressuposto do contrato eleitoral expresso pelo voto.

\section{Proposições de maior destaque no atendimento}

Entre as proposições de maior repercussão social durante o período estão (Quadro 3): 
Quadro 3 - Demonstrativo da média de atendimento

\begin{tabular}{lcll}
\hline & \multicolumn{1}{c}{ Ementa } \\
\hline PL 5476/01 & 94,57 & Proíbe a cobrança de assinatura básica do telefone fixo. \\
\hline PL 3299/08 & 1,69 & Extingue o fator previdenciário. \\
\hline PEC 300/08 & 1,58 & Propõe piso salarial nacional para bombeiros e policiais. \\
\hline PEC 02/03 & 0,25 & Permite ao servidor público requisitado optar pela lotação funcional do órgão cedente para o cessionário. \\
\hline PL 4548/98 & 0,15 & Exclui das sanções penais a prática de atividade com animal doméstico ou domesticado. \\
\hline PL 4434/08 & 0,14 & Reajusta benefícios mantidos pelo regime geral de previdência social. \\
\hline PL 5829/05 & 0,13 & Cria 400 varas da Justiça Federal e juizados especiais. \\
\hline PEC 54/99 & 0,09 & Permite que pessoal não concursado integre quadro temporário em extinção. \\
\hline PL 3101/97 & 0,09 & Regulamenta atividades de perfuração, produção, refino e transporte de petróleo e derivados. \\
\hline PL 2295/00 & 0,07 & Fixa a jornada de trabalho dos enfermeiros, técnicos e auxiliares de enfermagem. \\
\hline PL 1135/91 & 0,05 & Descriminaliza o aborto provocado pela gestante ou com seu consentimento. \\
\hline PL 5394/09 & 0,05 & Fixa o piso salarial do fonoaudiólogo. \\
\hline PL 3765/08 & 0,05 & Regulamenta serviços sob o regime de embarque e confinamento (conhecido como 14 por 21). \\
\hline PDC 731/00 & 0,04 & Convoca plebiscito sobre a criação do Estado do Tapajós. \\
\hline PL 29/07 & 0,04 & Regulamenta as atividades de comunicação social eletrônica. \\
\hline Outras & 1,02 & Outras proposições
\end{tabular}

Fonte: Pesquisa de campo / base de dados Câmara Federal.

Os dados mostram uma concentração de interesse dos participantes em questões que dizem respeito a determinadas categorias profissionais e direitos trabalhistas, além de assuntos relacionados ao direito do consumidor. Das 12 propostas que receberam manifestações, sete delas dizem respeito a questões trabalhistas ou profissionais, incluindo temas como piso salarial de categorias e assuntos previdenciários. As demais dividem-se entre temas econômicos, com reflexos na vida cotidiana dos cidadãos (telefonia, comunicação, energia), e temas polêmicos como descriminalização do aborto.

É oportuno observar, no Quadro 3, que as proposições de maior repercussão social, como os interesses estão ligados a temas bastante individuais ou de grupos bem específicos. O campeão de demandas $(94,57 \%)$ é o projeto que proíbe a assinatura básica de telefonia fixa, seguido, com larguíssima diferença, pela proposta que extingue o fator previdenciário $(1,69 \%)$ e a proposta que propõe piso salarial nacional para bombeiros e policiais $(1,58 \%)$.

Os três temas de maior manifestação social estão vinculados aos interesses individuais e corporativos, situados na esfera econômica. Contudo, são assuntos da pauta legislativa e se caracterizam pela morosidade na resposta dos parlamentares em função do jogo político e das configurações de poder dos partidos, de entes subnacionais (interesses de alguns estados principalmente), além da disputa entre governo e oposição. Trata-se de três assuntos típicos da agenda que fica em tramitação durante anos, a fim de manter a visibilidade dos atores (especialmente os parlamentares), mas sem comprometê-los com uma resposta definitiva à sociedade. Assim, tais temas sempre voltam à tona nos debates, criam expectativas dos segmentos sociais envolvidos, mas permanecem em suspense político, em função da contabilidade parlamentar que se favorece pelo não compromisso imediato e definitivo. A votação, ou seja, o sim ou o não podem resultar em prejuízos eleitorais e políticos de curto prazo (e o mandato é de apenas quatro anos). Portanto, a tática é manter o assunto na agenda e aproveitar as oportunidades para fazer pronunciamentos a favor ou contra, a depender das circunstâncias, a fim de capitalizar com as indefinições e protelamentos.

Certamente, não se pode desconsiderar o peso que o projeto que extingue a taxa mensal de assinatura básica da telefonia fixa teve no período, com quase $95 \%$ das manifestações recebidas pelo 
serviço de interação. Trata-se de um dos projetos mais emblemáticos para se compreender as dinâmicas da relação entre representação e participação no caso do Disque-Câmara. Campanhas coletivas utilizaram a internet e as redes sociais em geral para motivar a participação dos cidadãos em relação à questão. Uma mobilização social maciça, mas que, mesmo assim, não resultou na apreciação da proposta pela Casa Legislativa. Em mais de dez anos de tramitação da proposta, o volume de manifestações, superou a quantidade necessária para a apresentação de um projeto de lei de iniciativa popular. Apesar disso, não houve nenhum impacto no âmbito da esfera da representação, ou seja, não resultou em ação institucional ou parlamentar específica. Por outro lado, da parte da população também não houve reação. Os cidadãos continuam a ligar e registrar seu apoio ao projeto, mas sem qualquer outro tipo de ação organizada ou de cobrança política mais decisiva da parte da instituição e dos parlamentares. A mobilização se limita à captação de indivíduos para acionarem o Disque-Câmara. Não há registro de cobranças dos cidadãos nem mesmo em termos de demandas de informação sobre o volume de manifestações favoráveis ao projeto.

Como mostra o quadro 3 , todos os demais itens obtiveram menos de $1 \%$ de demanda, ainda que se tratem de projetos de interesses pessoais e (ou) de grupos específicos, como a jornada de trabalho dos enfermeiros. Temas mais amplos, como grandes reformas, nem sequer são citados. Ou seja, o cidadão que utiliza o 0800 da Câmara deseja participar segundo seu interesse particular, ainda que muitas vezes mobilizado por campanhas em redes sociais - como temos observado com frequência no twitter e no facebook, principalmente - em relação a determinado tema.

Nesse quesito é oportuno correlacionar as manifestações recebidas pelo Disque-Câmara com o mapa da participação social realizado por Avritzer e Navarro (2003), a partir da atuação dos movimentos associativistas no País. Nesse mapeamento, o ranking é o seguinte: saúde, habitação, meio ambiente, direitos humanos e educação. Trata-se da participação social organizada e estimulada pelas entidades da sociedade civil, organizações não governamentais e movimentos religiosos e comunitários. No caso do Disque-Câmara, trata-se da participação em menor escala, de menor densidade coletiva, apesar das redes de mobilização pela internet a favor ou contra determinado projeto de lei, como já foi abordado anteriormente. Nessa escala de participação, a motivação parece ser mais individualizada, sem correlação com a participação organizada em prol dos grandes temas nacionais apontados pelos autores citados.

\section{Tipologia das mensagens recebidas}

A tipologia dos registros das manifestações dos cidadãos foi implementada em 2004. Assim, os dados abaixo referem-se ao período de 2004-2011, distribuídos da seguinte forma, em termos quantitativos (Quadro 4).

O total de manifestações apurado no período é de 1.936.409 (um milhão, novecentos e trinta e seis mil, quatrocentos e nove). Quase 75\% dessas manifestações dos cidadãos foram considerações sobre proposições legislativas, ou seja, sobre propostas em análise pelos deputados. Esse dado indica que há um expressivo corpo de participantes que possui discernimento sobre a função desse canal de contato com a instituição legislativa. Em primeiro lugar, portanto, seu objetivo é manifestar sua opinião, buscando influenciar a decisão parlamentar sobre os assuntos que lhe interessam. Por outro lado, há indícios também de que segmentos populares utilizam o canal sem esse discernimento político, pautados na crença pessoal de que uma ligação telefônica poderá funcionar como um contato pessoal entre representado e representante, uma espécie de contato eleitoral direto, nos moldes da cultura política da reciprocidade e das relações interpessoais dos contextos paroquiais.

Mas, como se trata de um universo de participantes muito heterogêneo, também há registros de cidadãos interessados, conforme nos mostra a tipologia das mensagens, em tirar dúvidas sobre a atuação das comissões, dos deputados, propostas, bem como acompanhar o andamento de determinados assuntos ou serviços da Câmara (10,9\%). Muito mais do que em fazer solicitações a deputados e comissões $(2,8 \%)$, ou críticas e eles e a serviços $(1,2 \%)$. Solicitações, reclamações, sugestões e denúncias, em conjunto, não chegam ao mesmo patamar, mas também compõem o mosaico de tipos de participação possíveis por meio do Disque-Câmara. Ou seja, no heterogêneo escopo do universo dos participantes, presume-se que também haja segmentos do público 
Quadro 4 - Demonstrativo da média de atendimento

\begin{tabular}{|c|c|c|}
\hline Manifestações sobre proposições & $74,7 \%$ & Manifestação dos cidadãos sobre proposições em tramitação na Casa. \\
\hline Informações & $10,9 \%$ & Informações sobre Comissões, Deputados, Proposições e Serviços da Câmara. \\
\hline Outras & $7,7 \%$ & $\begin{array}{l}\text { Ligações utilizadas para desabafo pessoal, trote, chamadas interrompidas ou } \\
\text { linha muda. }\end{array}$ \\
\hline Solicitações aos Deputados e Comissões & $2,8 \%$ & Solicitações para os Deputados ou Comissões. \\
\hline Reclamações e Críticas & $1,2 \%$ & Reclamações ou críticas encaminhadas aos Deputados ou serviços da Câmara. \\
\hline Solicitações às Unidades Administrativas & $1,1 \%$ & Solicitações para Unidades Administrativas da Câmara. \\
\hline Sugestões & $0,7 \%$ & Sugestões para Deputados, Comissões e Unidades Administrativas da Câmara. \\
\hline Congratulações e Agradecimentos & $0,4 \%$ & $\begin{array}{l}\text { Mensagens de congratulação ou agradecimento aos Deputados ou a } \\
\text { serviços da Câmara. }\end{array}$ \\
\hline Participações nos veículos da Casa & $0,4 \%$ & Participação interativa do cidadão com veículos da Casa (debates, enquetes). \\
\hline Denúncias & $0,1 \%$ & Denúncias encaminhadas a CPIs, Comissões, Ouvidoria ou Deputados. \\
\hline
\end{tabular}

Fonte: Pesquisa de campo / base de dados Câmara Federal.

do Disque-Câmara que não tem interesse em uma relação pessoal com parlamentares, mas sim deseja usar o canal para manifestar-se sobre temas em debate no Congresso Nacional ou, mais especificamente, para fazer pressão política sobre os parlamentares. Não é possível generalizar e nem focar a análise em apenas um dos extremos. De certa forma, ainda que não haja igual participação de todos, umas das características da esfera pública, há de fato uma tentativa de diálogo, participação, e de influenciar na decisão parlamentar, preceito fundamental da democracia deliberativa. Assim, seja o cidadão que tenta utilizar o serviço como se fosse algo instrumental para um contato direto e interpessoal com os parlamentares, seja aquele com maior consciência cívica, todos, a seu modo, tentam dialogar com a instituição e com seus representantes.

Chama atenção ainda a conotação positiva da participação ${ }^{2}$, com o foco no acompanhamento dos debates e na tramitação de projetos de leis, com $74,7 \%$. A participação negativa apresenta percentuais baixíssimos: 1,2\% de reclamações e críticas; e 0,1\% de denúncias. Considerando a imagem negativa do Poder Legislativo perante a opinião pública, já demonstrada por várias pesquisas, esse elevado grau de participação positiva chama atenção e mereceria ser aprofundado (em outro artigo, talvez). Isso porque esses dados podem nos fazer questionar uma relação de causa e efeito que tem sido colocada há muito tempo: de que uma imagem negativa contribui para a apatia, desconfiança e, logo, falta de vontade de saber e participar. Os dados mostram que, apesar disso, há grande manifestação de interesse em saber mais e opinar. Isso pode indicar perspectivas de que a cultura de participação social no Brasil está in progress e que mesmo experiências em pequena escala devem ser consideradas e analisadas (AVRITZER, 1999), a exemplo do Disque-Câmara.

\section{Conclusões}

Os dados apresentados mostram que muitas das características sociais, demográficas e culturais do Brasil são reproduzidas no perfil dos cidadãos que participam pelo Disque-Câmara. Isso inclui as diferenças regionais e a concentração de manifestações nos estados do Sudeste (São Paulo, Rio

\footnotetext{
2 Considera-se participação positiva, para efeitos da análise aqui exposta, as manifestações que fogem ao escopo de crítica, reclamação e denúncia, ou seja, que expressam o desejo do cidadão de acompanhar o processo legislativo e tentar interferir no processo decisório. A participação negativa seria, portanto aquela cujo foco são as queixas e críticas, isto é, o que reforça a imagem negativa do Congresso Nacional.
} 
de Janeiro e Minas Gerais), com uma participação expressiva também dos estados mais populosos das regiões Nordeste (Pernambuco e Bahia) e Sul (Rio Grande do Sul).

Destaca-se também a concentração da participação de cidadãos com níveis de escolaridade mais elevados, especialmente aqueles com Ensino Superior $(50 \%)$. Infelizmente, a possibilidade de opinar sobre um assunto em debate no Legislativo pressupõe um nível de informação mínimo sobre as propostas em análise na Câmara, além do conhecimento básico sobre os canais de participação disponíveis, tais como Disque-Câmara. Como ressalta Gomes (2008), a participação requer um "volume adequado de conhecimento político estrutural e circunstancial e um estoque apropriado de informações não distorcidas e relevantes " para que o cidadão tenha níveis adequados de compreensão das matérias relativas aos negócios públicos e também ao jogo político (GOMES, 2008,p. 294). Além disso, o acesso aos debates públicos, a possibilidade de participação em instituições democráticas ou grupos de pressão e oportunidades eficazes de comunicação da esfera civil com seus representantes são essenciais no processo (GOMES, 2008, p. 294). O que os dados apresentados indicam é que a oportunidade de participação pelo Disque-Câmara - que envolve não apenas o conhecimento do canal ou uso do telefone, mas as demais condições mencionadas - não parece ser a mesma para todos os brasileiros.

Apesar de aa criação de canais cada vez mais sofisticados de participação ser uma tarefa que muitas instituições públicas têm desenvolvido, é importante lembrar, contudo, que as novas ferramentas de participação, sejam digitais ou analógicas como o Disque-Câmara, não eliminam os obstáculos tradicionais à participação política: falta de informação, apatia e desconexão entre cidadão e representante (MAIA, 2011, p. 68). E tampouco eliminam as desigualdades que permeiam a sociedade brasileira e que acabam transparecendo no processo.

Cabe ressaltar, ainda, os obstáculos decorrentes das idiossincrasias dos sistemas políticos e burocráticos. Um desses entraves resulta na impossibilidade de acompanhamento e cobrança de resposta pelos gabinetes parlamentares e pelos órgãos administrativos da Câmara. Nem o cidadão e nem os gestores do sistema podem acompanhar e cobrar, uma vez que o Disque-Câmara é subordinado à esfera administrativa da instituição, sem poderes de interferir ou opinar na gestão da informação nos gabinetes parlamentares e na hierarquia superior da burocracia administrativa. Tal característica é objeto de frequentes reclamações dos usuários que sequer podem contar com um número de protocolo para acompanhar o andamento das solicitações, uma vez que o sistema do Disque-Câmara limita-se a receber a manifestação, crítica ou sugestão do cidadão e repassar aos gabinetes, mas não há integração entre a plataforma tecnológica do 0800 e o sistema de informações dos gabinetes. Por isso a impossibilidade técnica de fornecer protocolo. Por outro lado, do ponto de vista da gestão da participação, tais mecanismos também podem ser avaliados como viabilizadores da interatividade, inclusive para garantir o registro das informações e a posterior extração de dados para relatórios estatísticos.

Além disso, há interesse ostensivo dos gabinetes e órgãos administrativos da Câmara em não receber as manifestações da sociedade coletadas pelo Disque-Câmara. Levantamento realizado pelos gestores do serviço em 2009 mostrou que $97 \%$ dos gabinetes deletam as mensagens da população sem ler. Dezenas de gabinetes, secretários de comissão e diretores de órgãos administrativos reclamam com frequência aos gestores do Disque-Câmara porque não gostariam de receber as mensagens da população. A alegação mais comum é a de que as mensagens não são passíveis de ser respondidas com objetividade e que muitas não são compreensíveis, não são claras ou são redundantes e desconexas.

Pesquisa realizada com os gestores de informação dos gabinetes em 2011 (SANTANA, 2011) mostra que os gabinetes alegam falta de infraestrutura e de pessoal qualificado para fazer a triagem e o atendimento das mensagens recebidas pelo Disque-Câmara. A mesma pesquisa concluiu que não há uma política comum para os gabinetes em termos de como lidar com a participação popular. Cada gabinete tem autonomia para decidir como lhe convém e nem sempre a decisão é do próprio deputado, mas do secretário parlamentar ou outro funcionário responsável pela caixa de e-mail institucional oferecida pela Câmara. Na prática, "raramente uma mensagem é mostrada ao deputado " (SANTANA, 2011, p. 52). Além disso, mais de $30 \%$ dos gabinetes sequer têm conhecimento das 
atribuições do Disque-Câmara. A mesma pesquisa mostra que dos 513 gabinetes, 188 não conhecem o serviço e nem sabem quais são as suas atribuições.

Além das condições inerentes à própria participação social, é necessário considerar os conflitos institucionais e políticos e as dissonâncias de valores entre a esfera burocrática e a estrutura política da instituição. Há uma assimetria entre o modelo de gestão institucional e os padrões de administração dos gabinetes, o que faz com que essas estruturas "pareçam pertencer a duas instituições diferentes e, dessa forma, como poderia a Câmara ser eficiente mantendo unidades tão assimétricas?" (SANTANA, 2011, p. 64). Em resumo, falta a definição mais clara de um arranjo institucional, a partir de uma aliança estratégica entre os dirigentes da esfera política e os gestores dos sistemas burocráticos, além de interesse dos partidos, lideranças e comissões. Em outras palavras, para que a participação social seja valorizada e possa produzir eficácia política, seria necessário que a instituição construísse as condições internas, priorizando um arranjo institucional de base racional, pautado na ética da responsabilidade e respaldado por um planejamento estratégico eficiente, incluindo um sistema de avaliação permanente do serviço e reforço aos princípios e às diretrizes da comunicação pública e seu potencial para consolidar projetos de transparência e de participação social.

\section{Referências}

AVRITZER, L. Teoria democrática, esfera pública e participação local. Sociologias, Porto Alegre, v. 1, n. 2, p. 18-41, jul./dez, 1999.

AVRITZER, L. Teoria democrática e deliberação pública. Lua Nova, São Paulo, n. 50, p. 25-46, 2000.

AVRITZER, L.; NAVARRO,Z.A Anovação democrática no Brasil: o orçamento participativo. São Paulo: Cortez, 2003.

BOBBIO, N. Estado, governo, sociedade: para uma teoria geral da política. 12.ed. Rio de Janeiro: Paz e Terra, 2005.
DINIZ, E. A reforma do Estado: uma nova perspectiva analítica. In: COELHO, M. F. et al. (Org.). Política, ciência e cultura em Max Weber. Brasília: EdUnB, 2000. p. 127-150.

FAUSTO, B. História do Brasil. São Paulo: Edusp, 1994.

GOMES, W. Internet e participação política. In: GOMES, W.; MAIA, R. C. M. Comunicação e democracia: problemas e perspectivas. São Paulo: Paulus, 2008. p. 293-326.

HABERMAS, J. Three normative models of democracy. Constellations, v. 1, n. 1, p. 1-10, 1994.

HANNERZ, U. Fluxos, fronteiras, híbridos: palavraschave da antropologia transnacional. Mana, Rio de Janeiro, v. 3, n. 1, p. 7-39, abr. 1997.

MAIA, R. C. M. Internet e esfera civil: limites e alcances da participação política. In: MAIA, R. C. M.; GOMES, W.; MARQUES, F. P. J. A. (Org.). Internet e participação política no Brasil. Porto Alegre: Sulina, 2011. p. 47-91.

MESSENBERG, D. A elite parlamentar brasileira: um recorte sociocultural. Revista de Sociologia e Política, Curitiba, v. 16, n. 30, p. 17-28, jun. 2008.

SANTANA, D. D. F. Uso das informações da Central de Comunicação Interativa da Câmara dos Deputados pelos gabinetes parlamentares. Monografia (Especialização) - Curso em Gestão Pública Legislativa, Câmara dos Deputados, Centro de Formação, Treinamento e Aperfeiçoamento (Cefor), 2011.

SANT"ANNA, F. Mídia das fontes: o difusor do jornalismo corporativo. Brasília: Casa das Musas, 2008.

ZÉMOR, P. La Communication Publique. Paris: PUF, 1995.

Recebido: $18 / 09 / 2012$ Received: 09/18/2012

Aprovado: 23/10/2012

Approved: 10/23/2012 